\section{AGRIEKONOMIKA}

http://journal.trunojoyo.ac.id/agriekonomika

Volume 9, Nomor 1, 2020

https://doi.org/10.21107/agriekonomika.v9i1.6440
Agriekonomika has been accredited as a scientific journal by the Ministry of

Research-Technology and Higher

Education Republic of Indonesia: No. 23/E/KPT/2019

SINTA 2

\title{
Model Peramalan Inflasi Bahan Makanan Primer dengan Pendekatan Box-Jenkins: Studi kasus di Kota Palu
}

\author{
${ }^{\square}$ Rustam Abd. Rauf, Arifuddin Lamusa, Samsul Bahri, M.Alfit A. Laihi, Effendy \\ Tadulako University, Indonesia \\ Received: January 2020; Accepted: April 2020; Published: April 2020
}

\begin{abstract}
ABSTRAK
Inflasi merupakan naiknya harga barang dan jasa secara umum dan berkelanjutan pada periode tertentu. Inflasi pada umumnya disebabkan oleh peningkatan permintaan agregat, kenaikan biaya produksi serta perkiraan nilai inflasi pada masa yang akan datang. Inflasi merupakan data deret waktu yang sulit diprediksi karena mengandung komponen tren, musiman, siklus, dan acak. Penelitian ini bertujuan untuk mencari model terbaik inflasi bahan makanan primer, menggunakan model ARIMA. Model terbaik yang diperoleh berdasarkan subkelompok bahan makanan adalah padi-padian, umbi-umbian, dan hasil-hasilnya (25,0,4); daging dan hasil-hasilnya (2,0,10); ikan segar (2,0,8); ikan diawetkan (2,0,8); telur, susu, dan hasil-hasilnya (12,0,20); sayur-sayuran (12,0,12); kacang-kacangan (14,0,13); buah-buahan (8,0,1); bumbu-bumbuan (1,0,1); lemak dan minyak $(19,0,0)$ dan bahan makanan lainnya $(25,0,3)$.
\end{abstract}

Kata Kunci: Deret Waktu, Inflasi, ARIMA

Inflation Forecasting Model of Primary Food Materials with Box-Jenkins Approach:

A Case Study in Palu City

\begin{abstract}
Inflation is an increase in the price of goods and services in general and continuously in a certain period. Inflation is generally caused by an increase in aggregate demand, an increase in production costs, and an inflation value estimation in the future. Inflation is a time-series data that is difficult to predict because it contains trend, seasonal, cycle, and random components. This study aimed to find the best model of primer food ingredients inflation, used the ARIMA model. The best models obtained based on the sub-group of food ingredients were grains, tubers, and its products $(25,0,4)$; meat and its products (2,0,10); fresh fish (2,0,8); preserved fish (2,0,8); eggs, milk, and its products $(12,0,20)$; vegetables $(12,0,12)$; legumes $(14,0,13)$; fruits $(8,0,1)$; spices $(1,0,1)$; fats and oils $(19,0,0)$ and other food ingredients $(25,0,3)$.
\end{abstract}

Keywords: Time Series, Inflation, ARIMA

\section{PENDAHULUAN}

Inflasi merupakan kecenderungan meningkatnya harga-harga barang dan jasa secara umum (Cheng \& Tan, 2002; Huang dkk., 2019). Inflasi disebabkan antara lain karena adanya permintaan masyarakat yang tinggi terhadap barang dan jasa, kenaikan biaya produksi, dan ekspektasi terhadap tingkat inflasi diwaktu yang akan datang (Adrián Risso \& Sánchez Carrera, 2009; Roncaglia de Carvalho, Ribeiro, \& Marques, 2018).Indikator yang sering digunakan untuk mengukur tingkat inflasi adalah indeks harga konsumen (Lee \& Kim, 2018; Pincheira-Brown dkk., 2019).

Penghitungan indeks harga konsumen (IHK) Kota Palu pertama kali dilakukan pada tahun 1990, mencakup 220 jenis paket p-ISSN 2301-9948 | e-ISSN 2407-6260 
komoditas barang/jasa yang diperoleh dari hasil Survei Biaya Hidup (SBH) tahun 1989. Seiring dengan perkembangan teknologi, perubahan tingkat pendapatan masyarakat, pola penawaran dan permintaan atas barang/jasa, serta peningkatan kualitas dan kuantitas barang/ jasa yang beredar di pasaran maka setiap lima tahun BPS melaksanakan SBH untuk mengetahui perubahan pola konsumsi dan perkembangan jenis komoditas yang diperdagangkan di wilayah Kota Palu. Sejak Januari 2014, penghitungan inflasi secara nasional telah menggunakan indeks harga konsumen (IHK) tahun dasar baru $(2012=100)$ yang didasarkan pada SBH 2012 yang dilaksanakan oleh BPS di 82 kota yang terdiri dari 33 ibukota provinsi dan 49 kota besar lainnya. Jumlah paket komoditas yang dipantau dalam penghitungan IHK dan inflasi Kota Palu hasil SBH 2012 ditetapkan sebanyak 346 komoditas (Badan Pusat Statistik, 2016).

Inflasi bahan makanan primer sangat penting untuk diramalkan karena dapat menjaga stabilitas pasar. Inflasi yang tidak stabil dapat memengaruhi kegiatan produksi dan penentuan harga bahan makanan primer. Inflasi yang rendah dan stabil dapat mendukung terpeliharanya daya beli masyarakat (Ahmed \& Abdelsalam, 2017; Hedenstierna, 2018). Peramalan tingkat inflasi yang tepat dan akurat diwaktu yang akan datang sangat diperlukan agar para pelaku usaha dapat melakukan perencanaan yang matang dalam melakukan kegiatan bisnis (Arlt \& Arltova, 2015; Lidiema, 2017). Peramalan tingkat inflasi juga diperlukan oleh pemerintah untuk mengambil kebijakan perekonomian di suatu daerah. Dalam melakukan suatu investasi, masyarakat umum juga perlu mengetahui peramalan tingkat inflasi (Aiken, 1999; Fukuda \& Soma, 2019).

Salah satu metode statistik untuk menganalisis data deret waktu adalah ARIMA (Autoregressive Integrated Moving Average). Metode ini dikembangkan oleh George EP Box dan Gwilym M Jenkins pada tahun 1976, sehingga model ini biasa disebut dengan metode BoxJenkins. Kelebihan metode ini yaitu hanya menggunakan nilai masa lalu dan masa sekarang dari variabel dependen untuk menghasilkan peramalan (Khashei, Bijari, \& Raissi Ardali, 2012; Yuan, Liu, \& Fang, 2016). Peramalan yang didapatkan dari metode ini lebih akurat dibandingkan dengan model ekonometrika tradisional lainnya dalam peramalan jangka pendek (Aasim, Singh, \& Mohapatra, 2019; Mills, 2019).

Tujuan penelitian iniuntuk memperoleh hasil peramalan nilai inflasi bahan makanan primer di Kota Palu. Hasil penelitian ini dapat menjadi rujukan bagi pemerintah daerah untuk membuat kebijakan dalam mengatur harga bahan primer menjelang hari-hari besar keagamaan.

\section{METODE PENELITIAN}

\section{Tempat dan sumber data}

Penelitian dilakukan di Kota Palu menggunakan data inflasi bahan makanan primer kota Palu selama 9 tahun dengan rentang waktu pengambilan data adalah bulan Januari 2010 sampai dengan bulan Desember 2018. Data yang digunakan dalam penelitian ini adalah data sekunder yang merupakan data deret waktu (time series) yaitu data inflasi bahan makanan primer kota Palu yang bersumber dari Badan Pusat Statistik (BPS) Kota Palu dan Badan Pusat Statistik (BPS) Sulawesi Tengah yang diakses melalui alamat website https://palukota.bps.go.id/ dan https://sulteng.bps.go.id/.

Data ini kemudian dikelompokkan setiap subkelompok bahan makanan berdasarkan bulan dan tahun, sehingga jumlah data yang dikumpulkan setiap subkelompok adalah 108 data. Inflasi bahan makanan primer terbagi atas 11 subkelompok bahan makanan yaitu : Padipadian, umbi-umbian, dan hasil-hasilnya; Daging dan hasil-hasilnya; Ikan segar; Ikan diawetkan; Telur, susu, dan hasil-hasilnya; Sayur-sayuran; Kacang-kacangan; Buahbuahan; Bumbu-bumbuan; Lemak dan minyak; Bahan makanan lainnya. 


\section{Penentuan Model Inflasi Bahan Makanan Primer}

Persamaan regresi peramalan untuk meramalkan nilai inflasi bahan makanan primer periode Januari 2019 hingga Desember 2020 tertera pada Tabel 1.

\section{Tabel 1}

Persamaan Regresi Peramalan Inflasi

\begin{tabular}{ccc}
\hline Variabel & $\begin{array}{r}\text { Persamaan Regresi Peramalan } \\
\text { Inflasi }\end{array}$ \\
\hline$Y_{1}$ & $Y_{1, t}=$ & $\left(1-\theta_{25}\right) \beta+\theta_{25} Y_{t-25}+\alpha_{4 \mathrm{e}} e_{t-4}$ \\
& $+\varepsilon_{t}$ \\
$Y_{2}$ & $Y_{2, t}=$ & $\left(1-\theta_{2}\right) \beta+\theta_{2} Y_{t-2}+\alpha_{10} e_{t-10}+\varepsilon_{t}$ \\
$Y_{3}$ & $Y_{3, t}=$ & $\left(1-\theta_{2}\right) \beta+\theta_{2} Y_{t-2}+\alpha_{8} e_{t-8}+\varepsilon_{t}$ \\
$Y_{4}$ & $Y_{4, t}=$ & $\left(1-\theta_{2}\right) \beta+\theta_{2} Y_{t-2}+\alpha_{8} e_{t-8}+\varepsilon_{t}$ \\
$Y_{5}$ & $Y_{5, t}=$ & $\left(1-\theta_{12}\right) \beta+\theta_{12} Y_{t-12}+\alpha_{20} e_{t-20}$ \\
& $+\varepsilon_{t}$ \\
$Y_{6}$ & $Y_{6, t}=$ & $\left(1-\theta_{12}\right) \beta+\theta_{12} Y_{t-12}+\alpha_{12} e_{t-12}$ \\
& $+\varepsilon_{t}$ \\
$Y_{7}$ & $Y_{7, t}=$ & $\left(1-\theta_{14}\right) \beta+\theta_{14} Y_{t-14}+\alpha_{13} e_{t-13}$ \\
& $+\varepsilon_{t}$ \\
$Y_{8}$ & $Y_{8, t}=$ & $\left(1-\theta_{8}\right) \beta+\theta_{8} Y_{t-1}+\alpha_{1} e_{t-1}+\varepsilon_{t}$ \\
$Y_{9}$ & $Y_{9, t}=$ & $\left(1-\theta_{1}\right) \beta+\theta_{1} Y_{t-1}+\alpha_{1} e_{t-1}+\varepsilon_{t}$ \\
$Y_{10}$ & $Y_{10, t}=$ & $\left(1-\theta_{19}\right) \beta+\theta_{19} Y_{t-19}+\varepsilon_{t}$ \\
$Y_{11}$ & $Y_{11, t}=$ & $\left(1-\theta_{25}\right) \beta+\theta_{25} Y_{t-25}+\alpha_{3} e_{t-3}$ \\
& $+\varepsilon_{t}$
\end{tabular}

Dimana $\mathbf{Y}_{1}$ adalah subkelompok padi padian, umbi-umbian, dan hasil-hasilnya. $\mathbf{Y}_{2}$ adalah subkelompok daging dan hasil-hasilnya. $\mathbf{Y}_{3}$ adalah subkelompok ikan segar. $\mathbf{Y}_{4}$ adalah subkelompok ikan diawetkan. $\mathbf{Y}_{5}$ adalah subkelompok telur, susu, dan hasil-hasilnya. $\mathbf{Y}_{6}$ adalah subkelompok sayur-sayuran. $\mathbf{Y}_{7}$ merupakan subkelompok kacangkacangan. $\mathbf{Y}_{8}$ adalah subkelompok buahbuahan. $\mathbf{Y}_{9}$ ialah subkelompok bumbubumbuan. $\mathbf{Y}_{10}$ adalah subkelompok lemak dan minyak, dan $\mathbf{Y}_{11}$ adalah subkelompok bahan makanan lainnya.

Model inflasi bahan makanan primer terbaik dipilih berdasarkan kriteria nilai adjusted $R^{2}$, kriteria informasi Akaike (AIC), dan kriteria informasi Schwarz (SIC). Apabila model yang memenuhi syarat tersebut lebih dari satu, maka dipilih lagi berdasarkan nilai Root Mean Square Error (RMSE). (Hong et al., 2016; Mentaschi, Besio, Cassola, \& Mazzino, 2013). Model yang memiliki nilai RMSE paling kecil merupakan model yang paling sesuai digunakan untuk peramalan.

Data inflasi bahan makanan primer yang telah dikelompokkan, diolah menggunakan aplikasi Eviews versi 10 untuk mencari model inflasi terbaik dan untuk meramalkan nilai inflasi periode 20192020. Model inflasi bahan makanan primer terbaik yang diperoleh pada setiap subkelompok bahan makanan, digunakan untuk meramalkan nilai inflasi setiap subkelompok bahan makanan untuk periode yang akan datang yaitu bulan Januari 2019 sampai dengan bulan Desember 2020.

\section{HASIL DAN PEMBAHASAN}

Hasil analisis model inflasi bahan makanan primer terbaik tertera pada Tabel 2 . Berdasarkan model inflasi bahan makanan primer terbaik pada Tabel 2 maka dapat diramalkan nilai inflasi setiap subkelompok bahan makanan primer untuk periode yang akan datang yaitu bulan Januari 2019 sampai dengan bulan Desember 2020.

\section{Padi-padian, Umbi-umbian, dan Hasil- hasilnya}

Peramalan nilai inflasi padi-padian, umbi-umbian, dan hasilnya tertera pada Tabel 3.Subkelompok padi-padian, umbiumbian, dan hasil-hasilnya terdiri atas komoditas beras, ketela pohon, mie basah, mie kering instant, tepung beras, dan tepung terigu.Berdasarkan perbandingan nilai inflasi padi-padian, umbi-umbian, dan hasil-hasilnya antara hasil peramalan dan nilai aktual, terlihat bahwa nilai peramalan pada tahun 2019 rata-rata lebih tinggi dari nilai inflasi aktual karena metode yang digunakan dalam peramalan ini adalah metode statik yang meramalkan nilai inflasi satu langkah kedepan sampai dengan waktu sekarang(Matyjaszek, Riesgo Fernández, Krzemień, Wodarski, \& Fidalgo Valverde, 2019; Torbat, Khashei, \& Bijari, 2018).Dibandingkan dengan nilai 
peramalan inflasi pada tahun 2020 ratarata nilai inflasi lebih rendah, mengingat perkiraan bulan Ramadhan dan Idul Fitri tahun 2020 adalah bulan April dan Mei, kemungkinan nilai inflasi aktual pada saat itu bisa lebih tinggi atau lebih rendah tergantung kebijakan pemerintah daerah provinsi Sulawesi Tengah dan Kota Palu dalam mengantisipasi situasi tersebut.

\section{Daging dan Hasil-hasilnya}

Peramalan nilai inflasi daging dan hasilhasilnya tertera pada Tabel 4 .
Nilai peramalan inflasi subkelompok daging dan hasil-hasilnya pada tabel 4 diatas berfluktuasi, dengan nilai inflasi terendah pada bulan Januari 2019 sebesar $-1.663 \%$ dan nilai inflasi tertinggi pada bulan Juli 2019 sebesar 2.472 \%. Apabila dibandingkan dengan nilai inflasi aktual pada bulan yang sama, nilai inflasi peramalan pada bulan Januari 2019 dan Februari 2019 mengalami penurunan (deflasi), hal ini diduga disebabkan oleh ketersediaan stok daging sapi potong yang berasal dari peternak lokal di Sulawesi

Tabel 2

Model Inflasi Bahan Makanan Primer di Kota Palu

\begin{tabular}{lcccccc}
\hline Subkelompok Bahan Makanan & Variabel & $\begin{array}{c}\text { Model ARIMA } \\
(\mathrm{p}, \mathrm{d}, \mathrm{q})\end{array}$ & Adj. $\mathrm{R}^{2}$ & AIC & SIC & RMSE \\
\hline Padi-padian, umbi-umbian dan & $\mathrm{Y}_{1}$ & $(25,0,4)$ & 0.090 & 4.199 & 4.299 & 1.816 \\
hasil-hasilnya & $\mathrm{Y}_{2}$ & $(2,0,10)$ & 0.198 & 4.620 & 4.719 & 2.349 \\
Daging dan hasil-hasilnya & $\mathrm{Y}_{3}$ & $(2,0,8)$ & 0.159 & 7.251 & 7.350 & 8.782 \\
Ikan segar & $\mathrm{Y}_{4}$ & $(2,0,8)$ & 0.143 & 5.094 & 5.194 & 2.974 \\
Ikan diawetkan & $\mathrm{Y}_{5}$ & $(12,0,20)$ & 0.103 & 2.530 & 2.630 & 0.792 \\
Telur, susu dan hasil-hasilnya & $\mathrm{Y}_{6}$ & $(12,0,12)$ & 0.080 & 6.930 & 7.029 & 6.778 \\
Sayur-sayuran & $\mathrm{Y}_{7}$ & $(14,0,13)$ & 0.041 & 5.107 & 5.207 & 3.183 \\
Kacang-kacangan & $\mathrm{Y}_{8}$ & $(8,0,1)$ & 0.216 & 6.745 & 6.844 & 6.415 \\
Buah-buahan & $\mathrm{Y}_{9}$ & $(1,0,1)$ & 0.009 & 3.344 & 3.444 & 1.245 \\
Bumbu-bumbuan & $\mathrm{Y}_{10}$ & $(0,0,19)$ & 0.103 & 3.813 & 3.887 & 1.708 \\
Lemak dan Minyak & $\mathrm{Y}_{11}$ & $(25,0,3)$ & 0.112 & 3.566 & 3.666 & 1.328 \\
Bahan Makanan lainnya & 2019 & & & & &
\end{tabular}

Sumber: Data Sekunder Diolah, 2019

Tabel 3

Peramalan Nilai Inflasi Padi-padian, Umbi-umbian, dan Hasil-hasilnya

\begin{tabular}{llllll}
\hline Tahun/Bulan & Nilai Ramalan & Nilai Aktual & Tahun/Bulan & Nilai Ramalan & Nilai Aktual \\
\hline Januari 2019 & 1.244 & -0.21 & Januari 2020 & 1.111 & \\
Februari 2019 & 0.651 & 1.03 & Februari 2020 & -0.662 & \\
Maret 2019 & 2.090 & -0.78 & Maret 2020 & 0.315 & \\
April 2019 & 1.800 & 0.72 & April 2020 & 1.184 & \\
Mei 2019 & 0.121 & 0.01 & Mei 2020 & 0.201 & \\
Juni 2019 & 0.469 & & Juni 2020 & 0.583 & \\
Juli 2019 & 0.434 & & Juli 2020 & 0.650 \\
Agustus 2019 & 0.961 & & Agustus 2020 & 0.917 \\
September 2019 & 1.127 & & September 2020 & 1.099 \\
Oktober 2019 & 0.539 & & Oktober 2020 & 0.603 & \\
November 2019 & 0.773 & & November 2020 & 0.004 & \\
Desember 2019 & 0.769 & & Desember 2020 & 0.741 & \\
\hline
\end{tabular}

Sumber: Data Sekunder Diolah, 2019 
Tengah cukup memadai, sehingga mampu memenuhi kebutuhan permintaan daging sapi di kota Palu,hal ini juga didukung oleh program pemerintah daerah Sulawesi Tengah yaitu populasi satu juta ekor sapi pada tahun 2021.

\section{Ikan Segar}

Peramalan nilai inflasi ikan segardi Kota Palu disajikan pada Tabel 5. Berdasarkan data inflasi bulanan setiap tahunnya, fluktuasi harga ikan segar biasanya semakin besar pada bulan Juli hingga
Desember, karena pada waktu tersebut curah hujan di Sulawesi Tengah cenderung meningkat sehingga berdampak pada berkurangnya aktivitas nelayan. Disamping itu, pada akhir tahun yaitu bulan Desember hingga Januari merupakan musim angin barat yang menyebabkan naiknya gelombang laut, sehingga nelayan enggan melaut karena cuaca buruk dan beresiko tinggi. Sedangkan pada bulan Januari hingga Juni merupakan musim kemarau yang juga merupakan musim angin timur dimana gelombang laut relatif lebih tenang

Tabel 4

Peramalan nilai inflasi daging dan Hasil-hasilnya

\begin{tabular}{lcclcc}
\hline Tahun/Bulan & $\begin{array}{c}\text { Nilai } \\
\text { Ramalan }\end{array}$ & Nilai Aktual & Tahun/Bulan & $\begin{array}{c}\text { Nilai } \\
\text { Ramalan }\end{array}$ & Nilai Aktual \\
\hline Januari 2019 & -1.663 & -2.63 & Januari 2020 & 0.192 \\
Februari 2019 & -0.300 & -1.70 & Februari 2020 & 0.352 & \\
Maret 2019 & 0.997 & 1.52 & Maret 2020 & 0.598 \\
April 2019 & 0.293 & 3.55 & April 2020 & 0.530 \\
Mei 2019 & -1.550 & 2.61 & Mei 2020 & 0.427 \\
Juni 2019 & 0.872 & & Juni 2020 & 0.456 \\
Juli 2019 & 2.472 & & Juli 2020 & 0.499 \\
Agustus 2019 & -0.374 & & Agustus 2020 & 0.487 \\
September 2019 & -1.136 & & September 2020 & 0.469 \\
Oktober 2019 & -0.231 & & Oktober 2020 & 0.474 \\
November 2019 & 1.157 & & November 2020 & 0.481 \\
Desember 2019 & 0.776 & & Desember 2020 & 0.479 \\
\hline
\end{tabular}

Sumber: Data Sekunder Diolah, 2019

Tabel 5

Peramalan Nilai Inflasi Ikan Sekar

\begin{tabular}{lcllcl}
\hline Tahun/Bulan & Nilai Ramalan & Nilai Aktual & Tahun/Bulan & Nilai Ramalan & Nilai Aktual \\
\hline Januari 2019 & 7.051 & 4.11 & Januari 2020 & 0.949 \\
Februari 2019 & -0.419 & -5.20 & Februari 2020 & 1.048 \\
Maret 2019 & 5.190 & -15.33 & Maret 2020 & 1.148 \\
April 2019 & -0.417 & 8.47 & April 2020 & 1.113 \\
Mei 2019 & 4.703 & 0.50 & Mei 2020 & 1.078 \\
Juni 2019 & -4.232 & & Juni 2020 & 1.090 \\
Juli 2019 & 4.446 & & Juli 2020 & 1.102 \\
Agustus 2019 & 2.193 & & Agustus 2020 & 1.098 \\
September 2019 & -0.085 & & September 2020 & 1.094 \\
Oktober 2019 & 0.710 & & Oktober 2020 & 1.095 \\
November 2019 & 1.512 & & November 2020 & 1.097 \\
Desember 2019 & 1.232 & & Desember 2020 & 1.096 & \\
\hline
\end{tabular}

Sumber: Data Sekunder Diolah, 2019 
sehingga aktivitas penangkapan ikan lebih optimal. Di bulan April 2019 kembali terjadi peningkatan nilai inflasi sebesar $8.47 \%$ yang disebabkan oleh permintaan terhadap ikan segar meningkat menjelang bulan Ramadhan, sedangkan pada bulan Mei 2019 terjadi penurunan inflasi sebesar $0.50 \%$ karena menjelang hari raya Idul Fitri permintaan terhadap ikan segar berkurang yang digantikan oleh peningkatan permintaan terhadap daging ayam dan daging sapi.

\section{Ikan Diawetkan}

Peramalan nilai inflasi ikan diawetkan tertera pada Tabel 6.Subkelompok ikan diawetkan terdiri atas komoditas ikan asin belah, ikan dalam kaleng, teri, dan udang kering. Ikan diawetkan khususnya ikan asin belah merupakan komoditas yang sangat bergantung dari pasokan ikan segar, apabila hasil tangkapan ikan segar berkurang, maka stok ikan asin belah juga berkurang, demikian juga berlaku untuk ikan teri dan udang kering. Stok ikan diawetkan juga dipengaruhi oleh cuaca selama proses pengeringan(Sotola et al., 2019). Melihat perkembangan nilai inflasi bulanan ikan diawetkan, khususnya pasca terjadinya gempa bumi, permintaan

Tabel 6

Peramalan Nilai Inflasi Ikan Diawetkan

\begin{tabular}{llllll}
\hline Tahun/Bulan & Nilai Ramalan & Nilai Aktual & Tahun/Bulan & Nilai Ramalan & Nilai Aktual \\
\hline Januari 2019 & -0.899 & 0.10 & Januari 2020 & 0.620 & \\
Februari 2019 & 2.714 & -4.24 & Februari 2020 & 0.675 \\
Maret 2019 & 1.389 & -2.07 & Maret 2020 & 0.636 \\
April 2019 & 0.240 & -4.65 & April 2020 & 0.621 \\
Mei 2019 & 0.508 & 5.01 & Mei 2020 & 0.632 \\
Juni 2019 & 1.688 & & Juni 2020 & 0.636 \\
Juli 2019 & 1.226 & & Juli 2020 & 0.633 \\
Agustus 2019 & -1.280 & & Agustus 2020 & 0.632 \\
September 2019 & 0.466 & & September 2020 & 0.633 \\
Oktober 2019 & 1.169 & & Oktober 2020 & 0.633 \\
November 2019 & 0.679 & & November 2020 & 0.633 \\
Desember 2019 & 0.482 & & Desember 2020 & 0.633 \\
\hline
\end{tabular}

Sumber: Data Sekunder Diolah, 2019

Tabel 7

Peramalan Nilai Inflasi Telur, Susu, dan Hasil-hasilnya

\begin{tabular}{|c|c|c|c|c|c|}
\hline Tahun/Bulan & Nilai Ramalan & Nilai Aktual & Tahun/Bulan & Nilai Ramalan & Nilai Aktual \\
\hline Januari 2019 & -0.334 & 0.63 & Januari 2020 & -0.102 & \\
\hline Februari 2019 & 0.372 & -1.04 & Februari 2020 & 0.350 & \\
\hline Maret 2019 & 0.517 & -1.85 & Maret 2020 & 0.352 & \\
\hline April 2019 & 0.326 & -2.79 & April 2020 & 0.169 & \\
\hline Mei 2019 & 0.915 & 2.19 & Mei 2020 & 0.719 & \\
\hline Juni 2019 & 0.270 & & Juni 2020 & 0.152 & \\
\hline Juli 2019 & 0.150 & & Juli 2020 & 0.202 & \\
\hline Agustus 2019 & 0.311 & & Agustus 2020 & 0.322 & \\
\hline September 2019 & 0.203 & & September 2020 & 0.291 & \\
\hline Oktober 2019 & 0.620 & & Oktober 2020 & 0.421 & \\
\hline November 2019 & 0.604 & & November 2020 & 0.416 & \\
\hline Desember 2019 & 0.567 & & Desember 2020 & 0.404 & \\
\hline
\end{tabular}

Sumber : Data Sekunder Diolah, 2019 
terhadap bahan makanan yang dapat bertahan lama meningkat, hal ini terlihat dari nilai inflasi ikan diawetkan pada bulan Oktober dan November 2018 meningkat masing-masing sebesar $0.87 \%$ dan 1.35 $\%$. Nilai inflasi ikan diawetkan kembali mengalami penurunan hingga $-2.66 \%$ pada bulan Desember 2018 yang disebabkan karena permintaan terhadap ikan diawetkan menurun, karena masyarakat kota Palu mulai beralih mengkonsumsi ikan segar.

Permintaan terhadap ikan diawetkan meningkat pada saat menjelang bulan
Ramadhan dan Idul Fitri dengan nilai inflasi aktual $5.01 \%$, nilai ini cukup tinggi apabila dibandingkan dengan nilai peramalan inflasi pada bulan yang sama dengan nilai $0.508 \%$.

\section{Telur, Susu, dan Hasil-hasilnya}

Peramalan nilai inflasi telur, susu dan hasilhasilnya tertera pada Tabel 7 . Subkelompok telur, susu dan hasil-hasilnya terdiri atas komoditas susu bubuk, susu kental manis, susu untuk balita, susu untuk bayi, susu untuk wanita hamil, telur ayam kampung, telur ayam ras, susu untuk tulang/manula,

Tabel 8

Peramalan Nilai Inflasi Sayur-sayuran

\begin{tabular}{llllll}
\hline Tahun/Bulan & Nilai Ramalan & Nilai Aktual & Tahun/Bulan & Nilai Ramalan & Nilai Aktual \\
\hline Januari 2019 & 0.147 & -1.70 & Januari 2020 & 0.178 & \\
Februari 2019 & -1.650 & 0.60 & Februari 2020 & -1.495 & \\
Maret 2019 & -2.386 & -5.95 & Maret 2020 & -2.180 & \\
April 2019 & -1.049 & 3.88 & April 2020 & -0.936 & \\
Mei 2019 & 0.034 & 20.19 & Mei 2020 & 0.073 \\
Juni 2019 & 5.253 & & Juni 2020 & 4.929 \\
Juli 2019 & 2.235 & & Juli 2020 & 2.121 \\
Agustus 2019 & 2.586 & & Agustus 2020 & 2.447 \\
September 2019 & -2.474 & & September 2020 & -2.262 \\
Oktober 2019 & 0.526 & & Oktober 2020 & 0.530 \\
November 2019 & 2.364 & & November 2020 & 2.240 \\
Desember 2019 & 1.832 & & Desember 2020 & 1.746 \\
\hline Sumber: Data Sekunder
\end{tabular}

Sumber: Data Sekunder Diolah, 2019

Tabel 9

Peramalan Nilai Inflasi Kacang-kacangan

\begin{tabular}{llllll}
\hline Tahun/Bulan & Nilai Ramalan & Nilai Aktual & Tahun/Bulan & Nilai Ramalan & Nilai Aktual \\
\hline Januari 2019 & 2.361 & -0.57 & Januari 2020 & -0.485 \\
Februari 2019 & -0.694 & -1.05 & Februari 2020 & 0.226 \\
Maret 2019 & 1.070 & -1.96 & Maret 2020 & 0.829 \\
April 2019 & -0.393 & -4.18 & April 2020 & 0.235 \\
Mei 2019 & 0.881 & 1.03 & Mei 2020 & 0.578 \\
Juni 2019 & 0.691 & & Juni 2020 & 0.294 \\
Juli 2019 & 1.304 & & Juli 2020 & 0.542 \\
Agustus 2019 & -0.916 & & Agustus 2020 & 0.505 \\
September 2019 & 1.335 & & September 2020 & 0.624 \\
Oktober 2019 & -0.563 & & Oktober 2020 & 0.192 \\
November 2019 & -2.038 & & November 2020 & 0.630 \\
Desember 2019 & 4.294 & & Desember 2020 & 0.261 & \\
\hline Sumb : Data Sekunder Diolah, 2019
\end{tabular}

Sumber : Data Sekunder Diolah, 2019 
susu cair kemasan, dan susu rendah lemak.

Berdasarkan tabel diatas, nilai peramalan inflasi subkelompok telur, susu dan hasil-hasilnya cenderung stabil, apabila dibandingkan dengan nilai inflasi aktual yang terus mengalami penurunan dari bulan Januari hingga April 2019 masingmasing sebesar $0.63 \%,-1.04 \%,-1.85 \%$ dan $-2.79 \%$. Menjelang bulan Ramadhan pada umumnya harga telur bergerak naik, tetapi nilai inflasi untuk subkelompok telur, susu, dan hasil-hasilnya cenderung mengalami deflasi, hal ini disebabkan karena kenaikan harga telur dapat diredam oleh pemerintah kota Palu dan Sulawesi Tengah melalui kegiatan inspeksi pasar dan kegiatan pasar murah. Disamping itu, pasokan telur yang berasal dari Kabupaten Tojo Una-una dan Sulawesi Barat dapat memenuhi kebutuhan masyarakat kota Palu. Menjelang hari raya Idul Fitri pada bulan Mei 2019, kebutuhan akan telur mengalami peningkatan, sehingga mengalami inflasi sebesar $2.19 \%$.

\section{Sayur-sayuran}

Peramalan nilai inflasi sayur-sayuran tertera pada Tabel 8. Subkelompok sayursayuran terdiri atas komoditas bayam, buncis, daun kelor, daun singkong, kacang panjang, kangkung, kentang, ketimun, kol putih/kubis, labu parang/ manis/merah, labu siam/jipang, nangka muda, sawi hijau, tauge/kecambah,terong panjang, tomat sayur, wortel, dan jagung manis. Sayuran merupakan komoditas yang memiliki umur panen yang pendek dan sangat dipengaruhi oleh cuaca dan merupakan komoditas yang cepat rusak. Berdasarkan pada tabel diatas, nilai inflasi subkelompok sayur-sayuran berfluktuasi, dari bulan Januari hingga Maret 2019 masing-masing sebesar $-1.70 \%, 0.60 \%$, dan $-5.95 \%$. Sedangkan menjelang bulan Ramadhan dan Idul Fitri, kebutuhan akan sayur mengalami peningkatan permintaan, dari nilai inflasi pada bula April dan Mei 2019 yang naik secara drastis dengan nilai inflasi masing-masing sebesar $3.88 \%$ dan 2019.

\section{Kacang-kacangan}

Peramalan nilai inflasi kacang-kacangan yang terjadi di Kota Palu disajikan Tabel 9. Subkelompok kacang-kacangan terdiri atas komoditas kacang hijau, kacang merah/joglo, kacang tanah, tahu mentah, dan tempe. Subkelompok ini merupakan komoditas yang memiliki nilai inflasi yang relatif stabil, hal ini terlihat dari nilai inflasi dari bulan Januari hingga April 2019

Tabel 10

Peramalan Nilai Inflasi Buah-buahan

\begin{tabular}{llllll}
\hline \multicolumn{1}{c}{ Tahun/Bulan } & $\begin{array}{c}\text { Nilai } \\
\text { Ramalan }\end{array}$ & Nilai Aktual & Tahun/Bulan & $\begin{array}{c}\text { Nilai } \\
\text { Ramalan }\end{array}$ & $\begin{array}{c}\text { Nilai } \\
\text { Aktual }\end{array}$ \\
\hline Januari 2019 & 0.012 & 1.52 & Januari 2020 & 0.022 & \\
Februari 2019 & -1.224 & -2.19 & Februari 2020 & 1.026 & \\
Maret 2019 & -0.522 & -2.82 & Maret 2020 & 0.505 & \\
April 2019 & 1.779 & 4.78 & April 2020 & 0.867 & \\
Mei 2019 & 2.380 & 12.27 & Mei 2020 & 0.515 & \\
Juni 2019 & -0.979 & & Juni 2020 & 0.405 \\
Juli 2019 & 0.763 & & Juli 2020 & 0.467 \\
Agustus 2019 & -0.447 & & Agustus 2020 & 0.673 \\
September 2019 & 0.729 & & September 2020 & 0.727 \\
Oktober 2019 & 1.099 & & Oktober 2020 & 0.427 \\
November 2019 & 0.889 & & November 2020 & 0.582 & \\
Desember 2019 & 0.201 & & Desember 2020 & 0.474 & \\
\hline
\end{tabular}

Sumber : Data Sekunder Diolah, 2019 
yang mengalami deflasi masing-masing sebesar $-0.57 \%,-1.05 \%,-1.96 \%$, dan $-4.18 \%$. Hal ini menandakan bahwa kebutuhan akan permintaan subkelompok kacang-kacangan khususnya tempe dan tahu di kota Palu masih rendah, sehingga stok kacang-kacangan yang ada dapat menjamin harga untuk tidak bergerak naik,sedangkan menjelang hari raya Idul Fitri pada bulan Mei 2019 kacangkacangan mengalami inflasi sebesar $1.03 \%$ karena meningkatnya permintaan kacang tanah untuk bahan pembuatan kue dan makanan lainnya.

\section{Buah-buahan}

Peramalan nilai inflasi buah-buahan tertera pada Tabel 10.Subkelompok buahbuahan terdiri atas komoditas anggur, apel, jeruk, nangka, pepaya, pir, pisang, salak, semangka, tomat buah, dan kelapa muda. Berdasarkantabel diatas, nilai inflasi buahbuahan cenderung stabil, hal ini terlihat dari nilai inflasi pada bulan januari hingga Maret 2019 dengan nilai masing-masing sebesar $1.52 \%,-2.19 \%$, dan $-2.82 \%$, hal ini menandakan bahwa pasokan buahbuahan yang berasal dari Sulawesi Tengah dan luar Sulawesi Tengah dapat memenuhi kebutuhan permintaan akan buah-buahan di kota Palu. Menjelang bulan Ramadhan dan Idul Fitri, permintaan akan buahbuahan cenderung meningkat sehingga mengalami kenaikan harga yang berakibat kenaikan inflasi untuk bulan April dan Mei 2019 masing-masing sebesar $4.78 \%$ dan $12.27 \%$.

Hal ini sejalan dengan nilai peramalan inflasi subkelompok buah-buahan yang mengalami peningkatan menjelang bulan Ramadhan dan Idul Fitri tetapi dengan nilai yang tidak ekstrim.

\section{Bumbu-bumbuan}

Peramalan nilai inflasi bumbu-bumbuan disajikan pada Tabel 11. Subkelompok bumbu-bumbuan merupakan komoditas yang relatif sulit ditebak pergerakan nilai inflasinya, hal ini disebabkan karena komoditas yang termasuk didalam subkelompok bumbu-bumbuan adalah cabe merah, cabe rawit, bawang merah dan bawang putih memiliki pola tanam yang berbeda-beda dan beberapa diantaranya didatangkan dari luar kota Palu sehingga rentan terhadap cuaca dan gangguan distribusi.Hal ini terlihat pada nilai inflasi aktual yang cenderung mengalami kenaikan pada menjelang bulan Ramadhan dan Idul Fitri.

Tabel 11, menunjukkan bahwa peramalan inflasi memiliki nilai yang relatif stabil dibandingkan dengan nilai aktual pada bulan Januari dan Februari 2019 mengalami deflasi, sedangkan menjelang bulan Ramadhan dan Idul Fitri 2019

Tabel 11

Peramalan Nilai Inflasi Bumbu-bumbuan

\begin{tabular}{|c|c|c|c|c|c|}
\hline Tahun/Bulan & Nilai Ramalan & Nilai Aktual & Tahun/Bulan & Nilai Ramalan & Nilai Aktual \\
\hline Januari 2019 & 1.719 & -0.67 & Januari 2020 & 1.649 & \\
\hline Februari 2019 & 1.583 & -2.83 & Februari 2020 & 1.640 & \\
\hline Maret 2019 & 1.692 & 0.21 & Maret 2020 & 1.647 & \\
\hline April 2019 & 1.605 & 8.36 & April 2020 & 1.641 & \\
\hline Mei 2019 & 1.675 & 6.86 & Mei 2020 & 1.646 & \\
\hline Juni 2019 & 1.619 & & Juni 2020 & 1.642 & \\
\hline Juli 2019 & 1.664 & & Juli 2020 & 1.645 & \\
\hline Agustus 2019 & 1.628 & & Agustus 2020 & 1.643 & \\
\hline September 2019 & 1.656 & & September 2020 & 1.645 & \\
\hline Oktober 2019 & 1.634 & & Oktober 2020 & 1.643 & \\
\hline November 2019 & 1.652 & & November 2020 & 1.644 & \\
\hline Desember 2019 & 1.637 & & Desember 2020 & 1.643 & \\
\hline
\end{tabular}

Sumber: Data Sekunder Diolah, 2019 
yaitu pada bulan Maret hingga Mei 2019, permintaan terhadap bumbu-bumbuan meningkat, utamanya cabe, bawang merah dan bawang putih sehingga menimbulkan inflasi. Bahkan, harga bawang putih pada saat bulan Ramadhan 2019 meningkat hampir mencapai 100 ribu Rupiah dari harga normalnya sebesar 25 ribu rupiah. Untuk menekan kenaikan harga bawang putih, pemerintah daerah Sulawesi Tengah menggelar operasi pasar dengan mendatangkan stok bawang putih dari pulau Jawa dengan harga 30 ribu per kilogram

\section{Lemak dan Minyak}

Peramalan nilai inflasi lemak dan minyak tertera pada Tabel 12. Subkelompok lemak dan minyak terdiri atas komoditas kelapa, margarin, minyak goreng, dan minyak kelapa.Nilai peramalan inflasi subkelompok ini relatif stabil pada kisaran kurang dari $1 \%$, bila dibandingkan dengan nilai inflasi aktual yang mengalami penurunan inflasi mulai dari bulan Januari 2019 dan relatif stabil hingga bulan April 2019, hal ini menandakan ketersediaan komoditas yang paling dibutuhkan menjelang hari-hari besar keagamaan seperti

Tabel 12

Peramalan Nilai Inflasi Lemak dan Minyak

\begin{tabular}{lcclcl}
\hline Tahun/Bulan & Nilai Ramalan & Nilai Aktual & Tahun/Bulan & Nilai Ramalan & Nilai Aktual \\
\hline Januari 2019 & 0.678 & 2.13 & Januari 2020 & 0.342 & \\
Februari 2019 & 0.449 & -0.06 & Februari 2020 & 0.539 & \\
Maret 2019 & 0.790 & -0.52 & Maret 2020 & 0.584 & \\
April 2019 & 0.589 & -0.20 & April 2020 & 0.365 & \\
Mei 2019 & 0.894 & 0.30 & Mei 2020 & 0.603 & \\
Juni 2019 & 0.552 & & Juni 2020 & 0.213 \\
Juli 2019 & 0.336 & & Juli 2020 & 0.498 \\
Agustus 2019 & 0.454 & & Agustus 2020 & 0.417 \\
September 2019 & 0.785 & & September 2020 & 0.417 \\
Oktober 2019 & 0.530 & & Oktober 2020 & 0.417 \\
November 2019 & 0.474 & & November 2020 & 0.417 & \\
Desember 2019 & 0.452 & & Desember 2020 & 0.417 & \\
\hline
\end{tabular}

Sumber: Data Sekunder Diolah, 2019

Tabel 13

Peramalan Nilai Inflasi Bahan Makanan Lainya

\begin{tabular}{|c|c|c|c|c|c|}
\hline Tahun/Bulan & Nilai Ramalan & Nilai Aktual & Tahun/Bulan & Nilai Ramalan & Nilai Aktual \\
\hline Januari 2019 & 0.573 & -0.04 & Januari 2020 & 0.525 & \\
\hline Februari 2019 & -0.133 & 1.13 & Februari 2020 & 0.224 & \\
\hline Maret 2019 & -0.142 & -0.89 & Maret 2020 & 0.485 & \\
\hline April 2019 & 0.838 & 0.91 & April 2020 & 0.733 & \\
\hline Mei 2019 & 0.110 & 0.00 & Mei 2020 & 0.709 & \\
\hline Juni 2019 & 0.437 & & Juni 2020 & 0.010 & \\
\hline Juli 2019 & 0.396 & & Juli 2020 & 0.375 & \\
\hline Agustus 2019 & 0.499 & & Agustus 2020 & 0.645 & \\
\hline September 2019 & 0.360 & & September 2020 & 0.974 & \\
\hline Oktober 2019 & 0.504 & & Oktober 2020 & 0.525 & \\
\hline November 2019 & 0.246 & & November 2020 & 0.375 & \\
\hline Desember 2019 & 0.530 & & Desember 2020 & 1.521 & \\
\hline
\end{tabular}

Sumber: Data Sekunder Diolah, 2019 
margarin dan minyak goreng dapat memenuhi kebutuhan permintaan kota Palu. Sedangkan menjelang hari raya Idul Fitri pada bulan Mei 2019 terjadi sedikit peningkatan nilai inflasi yang diakibatkan oleh naiknya permintaan.

\section{Bahan Makanan Lainnya}

Peramalan nilai inflasi bahan makanan lainnya tertera pada Tabel 13.Subkelompok bahan makanan lainnya terdiri atas komoditas bahan agar-agar, emping mentah, dan kerupuk udang. Subkelompok ini merupakan komoditas yang cenderung stabil, hal ini terlihat dari nilaiperamalan inflasi yang cenderung stabil dan hal ini juga sejalan dengan nilai aktual inflasi yang berkisar antara $0.00 \%$ hingga 1.13 $\%$. Penyebab kestabilan ini didukung oleh stok bahan makanan lainnya yang memadai yang dapat memenuhi kebutuhan masyarakat kota Palu, selain itu permintaan akan komoditas ini oleh usaha makanan jadi maupun konsumen rumah tangga masih tergolong rendah.

\section{SIMPULAN}

Hasil peramalan yang diperoleh dari model inflasi bahan makanan primer jika dibandingkan dengan nilai aktual inflasi, masih berada dalam batas interval kepercayaan $95 \%$, kecuali untuk beberapa periode peramalan yang keluar dari selang kepercayaan intervalnya, hal tersebut disebabkan karena adanya komponen musiman yang mempengaruhistasioneritas data dan kebijakan pemerintah daerah mengatur harga pangan menjelang hari tertentu seperti liburan dan hari besar keagamaan.

\section{DAFTAR PUSTAKA}

Aasim, Singh, S. N., \& Mohapatra, A. (2019). Repeated Wavelet Transform Based ARIMA Model for Very Short-term Wind Speed Forecasting. Renewable Energy, 136, 758-768. https://doi. org/10.1016/j.renene.2019.01.031.
Adrián Risso, W., \& Sánchez Carrera, E. J. (2009). Inflation and Mexican Economic Growth: Long-run Relation and threshold effects. Journal of Financial Economic Policy, 1(3), 246-263. https://doi. org/10.1108/17576380911041728.

Ahmed, D. A., \& Abdelsalam, M. A. M. (2017). Inflation Instability Impact on Interest Rate in Egypt: Augmented Fisher Hypothesis Test. Applied Economics and Finance, 5(1), 1 . https://doi.org/10.11114/aef. v5i1.2709.

Aiken, M. (1999). Using a neural network to forecast inflation. Industrial Management \& Data Systems, 99(7), 296-301. https://doi. org/10.1108/02635579910291984.

Arlt, J., \& Arltova, M. (2015). Forecasting of the Annual Inflation Rate in the Unstable Economic Conditions. 2015 Second International Conference on Mathematics and Computers in Sciences and in Industry (MCSI), 231-234. https://doi.org/10.1109/ MCSI.2015.34.

Badan Pusat Statistik. 2016.Indeks Harga Konsumen (IHK). Jakarta : BPS.

Cheng, M., \& Tan, H. (2002). Inflation in Malaysia. International Journal of Social Economics, 29(5), 411-425. https://doi. org/10.1108/03068290210423532.

Fukuda, S., \& Soma, N. (2019). Inflation target and anchor of inflation forecasts in Japan. Journal of the Japanese and International Economies, 52, 154-170. https://doi. org/10.1016/j.jjie.2019.01.002.

Hedenstierna, G. (2018). Unstable Inflation Is Harmful and More Common Supine Than Prone. American Journal of Respiratory and Critical Care Medicine, 198(2), 146-147. https:// doi.org/10.1164/rccm.2018020313ED. 
Hong, T., Kim, C.-J., Jeong, J., Kim, J., Koo, C., Jeong, K., \& Lee, M. (2016). Framework for Approaching the Minimum CV(RMSE) using Energy Simulation and Optimization Tool. Energy Procedia, 88, 265$270 . \quad$ https://doi.org/10.1016/j. egypro.2016.06.157.

Huang, H.-C., Yeh, C.-C., \& Wang, X. (2019). Inflation Targeting and Output-Inflation Tradeoffs. Journal of International Money and Finance, 96, 102-120. https://doi.org/10.1016/j. jimonfin.2019.04.009.

Khashei, M., Bijari, M., \& Raissi Ardali, G. A. (2012). Hybridization of Autoregressive Integrated Moving Average (ARIMA) with Probabilistic Neural Networks (PNNs). Computers \& Industrial Engineering, 63(1), 37-45. https://doi.org/10.1016/j. cie.2012.01.017.

Lee, S., \& Kim, Y. M. (2018). Inflation Expectation, Monetary Policy Credibility, and Exchange Rates. Finance Research Letters. https:// doi.org/10.1016/j.frl.2018.12.006.

Lidiema, C. (2017). Modelling and Forecasting Inflation Rate in Kenya Using SARIMA and Holt-Winters Triple Exponential Smoothing. American Journal of Theoretical and Applied Statistics, 6(3), 161. https://doi.org/10.11648/j. ajtas.20170603.15.

Matyjaszek, M., Riesgo Fernández, P., Krzemień, A., Wodarski, K., \& Fidalgo Valverde, G. (2019). Forecasting coking coal prices by means of ARIMA models and neural networks, considering the transgenic time series theory. Resources Policy, 61, 283-292. https://doi.org/10.1016/j. resourpol.2019.02.017.
Mentaschi, L., Besio, G., Cassola, F., \& Mazzino, A. (2013). Problems in RMSE-based wave model validations. Ocean Modelling, 72, 53-58. https://doi.org/10.1016/j. ocemod.2013.08.003.

Mills, T. C. (2019). ARIMA Models for Nonstationary Time Series. In Applied Time Series Analysis (pp. 57-69). https://doi.org/10.1016/ B978-0-12-813117-6.00004-1.

Pincheira-Brown, P., Selaive, J., \& Nolazco, J. L. (2019). Forecasting inflation in Latin America with core measures. International Journal of Forecasting, 35(3), 1060-1071. https://doi. org/10.1016/j.ijforecast.2019.04.011

Roncaglia de Carvalho, A., Ribeiro, R. S. M., \& Marques, A. M. (2018). Economic development and inflation: a theoretical and empirical analysis. International Review of Applied Economics, 32(4), 546-565. https:// doi.org/10.1080/02692171.2017.135 1531.

Sotola, V. A., Craig, C. A., Pfaff, P. J., Maikoetter, J. D., Martin, N. H., \& Bonner, T. H. (2019). Effect of preservation on fish morphology over time: Implications for morphological studies. PLOS ONE, 14(3), e0213915. https://doi.org/10.1371/ journal.pone.0213915.

Torbat, S., Khashei, M., \& Bijari, M. (2018). A hybrid probabilistic fuzzy ARIMA Model for Consumption Forecasting in Commodity Markets. Economic Analysis and Policy, 58, 22-31. https://doi.org/10.1016/j. eap.2017.12.003

Yuan, C., Liu, S., \& Fang, Z. (2016). Comparison of China's Primary Energy Consumption Forecasting by using ARIMA (The Autoregressive Integrated Moving Average) Model and $\operatorname{GM}(1,1)$ Model. Energy, 100, 384-390. https://doi.org/10.1016/j. energy.2016.02.001. 